\title{
TINJAUAN KEPUASAN PASIEN PADA PELAYANAN PENDAFTARAN RAWAT JALAN DI UPT RUMAH SAKIT KHUSUS MATA MEDAN TAHUN 2019
}

\author{
Erlindai \\ Dosen STIKes Imelda, Jalan Bilal Nomor 52 Medan \\ E-mail: erlindaipurba@gmail.com
}

\begin{abstract}
ABSTRAK
Pengukuran kepuasan pasien dilakukan karena kepuasan pasien merupakan tindakan dari layanan kesehatan yang diberikan tidak mungkin tepat sasaran dan berhasil tanpa melakukan pengukuran kepuasan pasien. Pengukuran kepuasan pasien pada fasilitas layanan kesehatan tidak mudah. Karena pengukuran kepuasan pasien harus dilakukan langsung kepada pasien, dan pasien tidak mungkin sulit mengetahui apakah layanan kesehatan yang didapatnya sudah sesuai dengan kebijakan rumah sakit. Tujuan penelitian ini untuk megetahui gambaran tingkat kepuasan pasien rawat jalan di unit pendaftaran di UPT Rumah Sakit Khusus Mata Medan Tahun 2018. Jenis penelitian ini menggunakan metode penelitian deskriptif yang merupakan penelitian yang digunakan untuk menggambarkan, dan menjelaskan kualitas atau keistimewaan dari pengaruh sosial yang tidak dapat dijelaskan, diukur atau digambarkan. Penelitian dilaksanakan pada bulan September-Februari 2019. Hasil penelitian ini ditemukan kepuasan Pasien Pada Pelayanan Pendaftaran Pasien Rawat Jalan di UPT Rumah Sakit Khusus Mata Medan, dijumpai populasi sebanyak 120 responden dan sampel sebanyak 30 responden yang telah diteliti, mayoritas kurang puas sebanyak 13 responden (43.3\%), dan minoritas puas sebanyak 5 responden (16.7\%), Kepuasan Pasien Pada Komunikasi Pendaftaran Pasien Rawat Jalan di UPT Rumah Sakit Khusus Mata medan dari 30 responden yang telah diteliti, mayoritas kurang puas sebanyak 13 responden (43.3\%), dan minoritas tidak puas sebanyak 8 responden (26.7\%), Kepuasan Pasien Pada Waktu Tunggu Pendaftaran Pasien Rawat Jalan di UPT Rumah Sakit Khusus Mata medan dari 30 responden yang telah diteliti, mayoritas tidak puas sebanyak 15 responden (50\%), dan minoritas puas sebanyak 3 responden (10\%). Saran kepada rumah sakit khusus Mata Medan agar dapat meningkatkan mutu pelayanan pada pendaftaran agar sesuai dengan prosedur yang berlaku.
\end{abstract}

Kata Kunci : : Kepuasan, Pasien Rawat Jalan

\begin{abstract}
The measurement of patient satisfaction is done because patient satisfaction is an act of health care provided it is not possible to be on target and succeed without measuring patient satisfaction. Measuring patient satisfaction at health care facilities is not easy. Because the measurement of patient satisfaction must be done directly to the patient, and the patient may not find it difficult to know whether the health services that are obtained are in accordance with hospital policy. The purpose of this study was to determine the description of the level of outpatient satisfaction in the registration unit at the UPT Medan Special Hospital in 2018. This type of research uses descriptive research methods which are studies used to describe, and explain the quality or privilege of social influences that cannot explained, measured or illustrated. The study was conducted in September-February 2019. The results of this study found patient satisfaction in Outpatient Patient Registration Services at the UPT Medan Special Hospital, found a population of 120 respondents and a sample of 30 respondents who had been studied, the majority were less satisfied as many as 13 respondents (43.3\%), and a minority satisfied as many as 5 respondents (16.7\%), Patient Satisfaction at Outpatient Patient Communication Communication at UPT Mata Field Special Hospital from 30 respondents who had been studied, the majority were less satisfied as many as 13 respondents (43.3\%), and minorities were not satisfied as many as 8 respondents (26.7\%), Patient Satisfaction At Waiting for Outpatient Patient Registration at the UPT Mata Mata Special Hospital of 30
\end{abstract}


respondents who had been studied, the majority were dissatisfied as many as 15 respondents (50\%), and a satisfied minority of 3 respondents (10\%). Suggestion for special hospital Mata Medan in order to improve the quality of service on registration so that it is in accordance with applicable procedures.

Keywords : Satisfaction, Outpatient.

\section{PENDAHULUAN}

Menurut WHO (World Health Organization), rumah sakit adalah bagian integral dari suatu organisasi sosial dan kesehatan dengan fungsi menyediakan pelayanan paripurna (komprehensif), penyembuhan penyakit (kuratif) dan pencegahan penyakit (prefentif) kepada masyarakat. Rumah sakit juga merupakan pusat pelatihan bagi tenaga kesehatan dan pusat penelitian medik (Ery Rustiyanto, 2009).

Menurut Permenkes No. 269/Mentri Kesehatan/Per/III/2008 Bab I Pasal 1 rekam medis adalah berkas yang berisikan catatan dokumen tentang identitas pasien, pemeriksaan, pengobatan, tindakan dan pelayanan lain kepada pasien pada sarana pelayanan kesehatan. Setiap rumah sakit menyelenggarakan rekam medis untuk meningkatkan mutu pelayanan kesehatan yang diberikan. Dalam Permenkes No. 269 MENKES/PER/III/2008 Bab III, pasal 7 bahwa sarana pelayanan kesehatan wajib menyediakan fasilitas yang diperlukan dalam rangka penyelenggaraan rekam medis.

Catatan medis adalah catatan yang berisikan data mengenai pasien mulai dari sebelum ia dilakukan, saat lahir, tumbuh menjadi dewasa hingga akhir hidupnya. Data ini dibuat bilamana pasien mengunjungi instansi pelayanan kesehatan baik pasien berobat rawat jalan maupun rawat inap (Ery Rustiyanto, 2009).

Menurut Huffman (Savitri C.B, 2011) pelayanan rawat jalan adalah pelayanan yang diberikan kepada pasien yang tidak mendapatkan pelayanan rawat inap difasilitas pelayanan kesehatan.Kegiatan ditempat penerimaan pasien tertulis dalam prosedur penerimaan pasien, sebaiknya prosedur diletakkan ditempat yang mudah dibaca oleh petugas penerimaan pasien.Hal ini dilakukan untuk mengontrol pekerjaan yang telah dilakukan sehingga pekerjaan yang dilakukan dapat konsisten dan sesuai aturan.Masalah yang sering dihadapi secara umum oleh rumah sakit adalah rumah sakit belum mampu memberikan suatu hal yang benar-benar diharapkan pengguna jasa.Untuk mendapatkan pelayanan yang diharapkan pasien, petugas rekam medis khususnya diunit pendaftaran rawat jalan.

Berdasarkan penelitian Laia (2011) di RSU Mitra Medika Medan, dari 92 responden, $(67,4 \%)$ responden menyatakan persepsi kehandalan petugas pendaftaran pasien baik, dan $(32,6 \%)$ menyatakan persepsi kehandalan petugas pendaftaran tidak baik, $(58,7 \%)$ responden menyatakan persepsi ketanggapan petugas baik, dan $(41,3 \%)$ responden menyatakan persepsi ketanggapan petugas tidak baik, $(71,7 \%)$ responden menyatakan persepsi petugas perhatian kepada pasien, dan $(28,3 \%)$ responden menyatakan persepsi perhatian petugas tidak baik.

Survei kepuasan pasien perlu dilakukan, oleh sebab itu, pengukuran kepuasan pasien dilakukan karena kepuasan pasien merupakan tindakan dari layanan kesehatan yang diberikan tidak mungkin tepat sasaran dan berhasil tanpa melakukan pengukuran kepuasan pasien. Pengukuran kepuasan pasien pada fasilitas layanan kesehatan tidak mudah. Karena pengukuran kepuasan pasien harus dilakukan langsung kepada pasien, dan pasien tidak mungkin sulit mengetahui apakah layanan kesehatan yang didapatnya sudah sesuai dengan kebijakan rumah sakit (Imbalo, 2017).

Berdasarkan survei awal yang dilakukan peneliti lakukan di UPT Rumah Sakit Khusus Mata Medan di unit pendaftaran pasien rawat jalan melalui wawancara peneliti kepada responden, dari 10 pasien rawat jalan terdapat 8 orang pasien yang menyatakan tidak puas dengan 
pendaftaran rawat jalan karena tidak ramahnya petugas terhadap pasien, dan 2 orang pasien menyatakan merasa puas dengan pelayanan pendaftaran rawat jalan dirumah sakit.

UPT Rumah Sakit Khusus Mata adalah salah satu binaan Dinas Kesehatan (Dinkes) Provinsi Sumatera Utara (SUMUT), resmi dibuka untuk beroperasi melayani masyarakat yang beralamat di Jalan Karya Medan.

Berdasarkan latar belakang masalah diatas, maka peneliti tertarik untuk melakukan penelitian tentang "Tinjauan Kepuasan Pasien Terhadap Pelayanan Pendaftaran Rawat Jalan Di UPT Rumah Sakit Khusus Mata Tahun 2018".

\section{Rumusan Masalah}

Berdasarkan latar belakang masalah diatas, maka penulis merumuskan masalah dalam penelitian ini adalah bagaimana tingkat kepuasan pasien rawat jalan diunit pendaftaran di UPT Rumah Sakit Khusus Mata Medan.

\section{Tujuan Penelitian}

Penelitian ini bertujuan untuk megetahui gambaran tingkat kepuasan pasien rawat jalan diunit pendaftaran di UPT Rumah Sakit Khusus Mata Medan Tahun 2018.

\section{Manfaat Penelitian}

1. Bagi Rumah Sakit

Hasil penelitian menjadi bahan masukan bagi rumah sakit sehingga dapat digunakan sebagai bahan pertimbangan untuk perbaikan dalam meningkatkan pelayanan di unit pendaftaran pasien rawat jalan.

2. Bagi Pendidikan

Sebagai referensi/bahan materi pengajaran di perpustakaan Prodi D-3 Rekam Medis dan Informasi Kesehatan STIKes Imelda Medan dan untuk penelitian lanjutan.

3. Bagi Peneliti

Menambah pengalaman dan pengetahuan penliti khususnya tingkat kepuasan pasien rawat jalan di unit pendaftaran pasien di UPT Rumah Sakit Khusus Mata Medan.

\section{METODE}

\section{Jenis Penelitian}

Jenis penelitian ini menggunakan metode penelitian deskriptif. Penelitian Deskriptif merupakan penelitian yang digunakan untuk menggambarkan, dan menjelaskan kualitas atau keistimewaan dari pengaruh sosial yang tidak dapat dijelaskan, diukur atau digambarkan (Saryono, 2008). Dalam penelitian ini, peneliti bermaksud memberikan deskripsi atau gambaran mengenai tingkat kepuasan pasien rawat jalan di unit pendaftaran di UPT Rumah Sakit Khusus Mata Tahun 2018.

\section{Tempat Penelitian}

Tempat penelitian dilaksanakan di UPT Rumah Sakit Khusus Mata Medan, Khususnya dibagian unit pendaftaran rawat jalan. UPT Rumah Sakit Khusus Mata Medan adalah salah satu binaan Dinas Kesehatan (Dinkes) Provinsi Sumatera Utara (SUMUT) yang beralamat di Jalan Karya Medan. Alasan peneliti mengambil tempat penelitian ini adalah peneliti sebelumnya telah melakukan wawancara kepada responden dan hasil mengatakan adanya kasus dalam pelayanan pendaftaran rawat jalan.

\section{Populasi}

Populasi adalah keseluruhan sumber data yang diperlukan dalam suatu penelitian (Saryono, 2013). Populasi penelitian ini adalah sebanyak 300 pasien.

\section{Sampel}

Sampel adalah sebagian atau wakil populasi yang diteliti. Sampel penelitian berdasarkan Arikunto (2010) bahwa apabila subjeknya kurang dari 100, lebih baik semua, tetapi jika subjeknya lebih dari 100, dapat diambil antara $10-15 \%$ atau $20-23 \%$ atau lebih dari jumlah populasi, maka sampel yang diambil adalah $10 \%$ dari pasien yang dirawat berjumlah 30 pasien. 


\section{Teknik Sampling}

Teknik sampling yang digunakan dalam penelitian ini adalah teknik Accidental Sampling, dimana pengambilan sampel ini dilakukan dengan pengambilan kasus atau responden yang kebetulan ada atau tersedia di tempat penelitian terjadi (Notoatmojo, 2012).

\section{Variabel}

Variabel merupakan ukuran atau ciri yang dimiliki oleh anggota-anggota suatu kelompok yang berbeda dengan yang dimiliki oleh kelompok lain (Saryono, 2013). Adapun variabel dalam penelitian ini adalah Pelayanan, Komunikasi dan Waktu Tunggu

\section{Definisi Operasional}

Untuk membatasi ruang lingkup atau pengertian variabel-variabel. Tersebut diberi batasan atau definisi operasional (Notoatmodjo, 2012).

Tabel 1. Definisi Operasional

\begin{tabular}{|c|c|c|c|c|c|c|c|}
\hline No & Nama & Defisi & $\begin{array}{l}\text { Alur } \\
\text { Ukur }\end{array}$ & Cara Ukur & $\begin{array}{l}\text { Nilai } \\
\text { Ukur }\end{array}$ & Hasil Ukur & $\begin{array}{l}\text { Skala } \\
\text { Ukur }\end{array}$ \\
\hline 1 & Pelayanan & $\begin{array}{l}\text { Meliputi pelayanan } \\
\text { keramahan petugas rumah } \\
\text { sakit, kecepatan dalam } \\
\text { pelayanan. Rumah sakit } \\
\text { dianggap lebih baik } \\
\text { apabila dalam } \\
\text { memberikan pelayanan } \\
\text { lebih memperhatikan } \\
\text { kebutuhan pasien maupun } \\
\text { orang lain yang } \\
\text { berkunjung dirumah sakit. }\end{array}$ & Kuisoner & $\begin{array}{l}\text { Pengisihan } \\
\text { kuisioner oleh } \\
\text { pasien } \\
\text { (responden) }\end{array}$ & $\begin{array}{l}\text { 1. } 10-23 \\
\text { 2. } 24-37 \\
\text { 3. } 38-50\end{array}$ & $\begin{array}{l}\text { 1.Tidak } \\
\text { Puas } \\
\text { 2.Kurang } \\
\text { Puas } \\
\text { 3. Puas }\end{array}$ & Ordinal \\
\hline 2 & Komunikasi & $\begin{array}{l}\text { Komunikasi adalah cara } \\
\text { petugas pendaftaran } \\
\text { mendapatkan informasi } \\
\text { dari pasien. }\end{array}$ & Kuisoner & $\begin{array}{l}\text { Pengisihan } \\
\text { kuisioner oleh } \\
\text { pasien } \\
\text { (responden) }\end{array}$ & $\begin{array}{l}\text { 1. } 10-23 \\
\text { 2. } 24-37 \\
\text { 3. } 38-50\end{array}$ & $\begin{array}{l}\text { 1.Tidak } \\
\text { Puas } \\
\text { 2.Kurang } \\
\text { Puas } \\
\text { 3. Puas } \\
\end{array}$ & Ordinal \\
\hline 3 & $\begin{array}{l}\text { Waktu } \\
\text { Tunggu }\end{array}$ & $\begin{array}{l}\text { Waktu tunggu adalah } \\
\text { yang digunakan pasien } \\
\text { untuk mendapatkan } \\
\text { pelayanan kesehatan } \\
\text { mulai dari pendaftaran } \\
\text { sampai masuk keruang } \\
\text { pemeriksaan dokter. }\end{array}$ & Kuisioner & $\begin{array}{l}\text { Pengisihan } \\
\text { kuisioner oleh } \\
\text { pasien } \\
\text { (responden) }\end{array}$ & $\begin{array}{l}\text { 1. } \\
\text { 1. } 5-11 \\
\text { 2. } 12-18 \\
\text { 3. } 19-25\end{array}$ & $\begin{array}{l}\text { 1.Tidak } \\
\text { Puas } \\
\text { 2.Kurang } \\
\text { Puas } \\
\text { 3. Puas }\end{array}$ & Ordinal \\
\hline
\end{tabular}

\section{Instrumen Penelitian}

Intrumen adalah alat atau fasilitas yang digunakan peneliti dalam mengumpulkan data agar pekerjaannya lebih mudah dan hasilnya lebih baik (cermat, lengkap dan sistematis) sehingga lebih mudah diolah (Saryono, 2013). Peneliti mengumpulkan data dengan menggunakan angket dengan jumlah pertanyaan sebanyak 20 item. Setiap item terdiri dari lima pilihan jawaban menurut skala Likert

\section{Cara Pengumpulan Data}

Peneliti mengumpulkan data tentang pelayanan dengan menggunakan angket dengan jumlah pertanyaan sebanyak 20 item. Angket yang digunakan adalah angket tertutup, yaitu angket yang sudah dilengkapi dengan jawaban. Setiap item terdiri dari lima pilihan jawaban menurut skala Likert. Untuk jawaban sangat tidak puas diberi skor 1, jawaban Tidak Puas diberi skor 2, jawaban Kurang Puas diberi skor 3, jawaban Puas dberi skor 4 dan jawaban Sangat Puas diberi skor 5. 
Skor tertinggi adalah 50(10x5) dan yang terendah $10(10 \times 1)$ sehingga rentang skor untuk Pelayanan 10-50.

$$
\begin{gathered}
\text { interval }=\frac{\text { nilai tertinggi-nilai terendah }}{\text { kelas }} \\
I=\frac{50-10}{3} \\
I=13,3=13
\end{gathered}
$$

Sehingga di dapat katagori:

1. Puas, jika skor mendapatkan 38-50

2. Kurang Puas, jika mendapatkan skor 24-37

3. Tidak Puas, jika mendapatkan skor 1023

Peneliti mengumpulkan data tentang komunikasi dengan menggunakan angket dengan jumlah pertanyaan sebanyak 10 item. Angket yang digunakan adalah angket tertutup, yaitu angket yang sudah dilengkapi dengan jawaban. Setiap item terdiri dari lima pilihan jawaban menurut skala Likert. Untuk jawaban sangat tidak puas diberi skor 1, jawaban Tidak Puas diberi skor 2, jawaban Kurang Puas diberi skor 3, jawaban Puas dberi skor 4 dan jawaban Sangat Puas diberi skor 5. Skor tertinggi adalah 50(10x5) dan yang terendah 10(10x1) sehingga rentang skor untuk Komunikasi 10-50.

Katagori tingkat kepuasan pasien terhadap komunikasi menggunakan rumus:

$$
\begin{gathered}
\text { interval }=\frac{\text { nilai tertinggi-nilai terendah }}{\text { kelas }} \\
I=\frac{50-10}{3} \\
I=13,3=3
\end{gathered}
$$

Sehingga di dapat katagori:

1. Puas, jika skor mendapatkan 38-50

2. Kurang Puas, jika mendapatkan skor 24-37

3. Tidak Puas, jika mendapatkan skor 1023

Peneliti mengumpulkan data tentang waktu tunggu dengan menggunakan angket dengan jumlah pertanyaan sebanyak 5 item. Angket yang digunakan adalah angket tertutup, yaitu angket yang sudah dilengkapi dengan jawaban. Setiap item terdiri dari lima pilihan jawaban menurut skala Likert. Untuk jawaban sangat tidak puas diberi skor 1, jawaban Tidak Puas diberi skor 2, jawaban Kurang Puas diberi skor 3, jawaban Puas dberi skor 4 dan jawaban Sangat Puas diberi skor 5.

Skor tertinggi adalah $25(5 \times 5)$ dan yang terendah $5(5 \times 1)$ sehingga rentang skor untuk waktu tunggu 5-25.

Katagori tingkat kepuasan pasien terhadap waktu tunggu menggunakan rumus:

$$
\begin{gathered}
\text { interval }=\frac{\text { nilai tertinggi-nilai terendah }}{\text { kelas }} \\
I=\frac{25-5}{3} \\
I=6,6=6
\end{gathered}
$$

Sehingga di dapat katagori:

1. Puas, jika skor mendapatkan 19-25

2. Kurang Puas, jika mendapatkan skor 12-18

3. Tidak Puas, jika mendapatkan skor 5-11.

\section{Teknik Pengolahan Data}

Dalam pengolahan data yang telah pengumpulan data pada penelitian antara lain:

1. Editing Data

Mengoreksi jawaban yang telah diberikan responden, apabila ada data yang salah atau kurang segera dilengkapi.

2. Coding Data

Melakukan pengkodean terhadap beberapa variable yang akan diteliti, dengan tujuan untuk mempermudah pada saat melakukan analisis data.

3. Penyajian Data

Suatu penyajian sistematik daripada data numerik, yang tersusun dalam kolom.

\section{Analisis Data}

Analisis secara deskriptif statistik dengan melihat persentase yang telah dikumpulkan dengan tabel distribusi frekuensi.Kemudian dicari besar persentase jawaban masing-masing respon dan selanjutnya dilakukan pembahasan hasil. Analisis Univariat adalah analisis yang dilakukan untuk satu variabel atau pervariabel. 
HASIL

\section{Analisis Univariat}

Tabel 2. Distribusi Frekuensi Berdasarkan Karakteristik Responden

\begin{tabular}{clcc}
\hline No & Karakteristik & F & $(\%)$ \\
\hline $\mathbf{1}$ & Umur & & \\
\hline & 21-30 Tahun & 5 & 16.7 \\
\hline & 31-40 Tahun & 10 & 33.3 \\
\hline$\quad$ 41-50 Tahun & 15 & 50 \\
\hline $\mathbf{2}$ & Jenis Kelamin & & \\
\hline$\quad$ Perempuan & 12 & 40 \\
\hline$\quad$ Laki-Laki & 18 & 60 \\
\hline $\mathbf{3}$ & Pendidikan & & \\
\hline & SMA & 6 & 20 \\
\hline$\quad$ D III & 10 & 33.3 \\
\hline & S I & 14 & 46.7 \\
\hline
\end{tabular}

Tabel diatas menunjukkan bahwa distribusi umur dari 30 responden yang telah diteliti, mayoritas 41-50 tahun sebanyak 15 responden $(50 \%)$, dan minoritas 21-30 tahun sebanyak 5 responden $(16.7 \%)$. Distribusi jenis kelamin dari 30 responden yang telah diteliti, mayoritas laki-laki sebanyak 18 responden $(60 \%)$, dan minoritas perempuan sebanyak 12 responden $(40 \%)$. Distribusi pendidikan dari 30 responden yang telah diteliti, mayoritas S I sebanyak 14 responden (46.7\%), dan minoritas SMA sebanyak 6 responden $(20 \%)$.

Tabel 3. Distribusi Frekuensi Kepuasan Pasien Pada Pelayanan Pendaftaran Pasien Rawat Jalan di UPT Rumah Sakit Khusus Mata Medan

\begin{tabular}{clcc}
\hline No & Pelayanan & F & $(\mathbf{\%})$ \\
\hline 1 & Tidak Puas & 12 & 40 \\
\hline 2 & Kurang Puas & 13 & 43.3 \\
\hline 3 & Puas & 5 & 16.7 \\
\hline & Total & $\mathbf{3 0}$ & $\mathbf{1 0 0}$ \\
\hline
\end{tabular}

Tabel diatas menunjukkan bahwa distribusi Kepuasan Pasien Pada Pelayanan Pendaftaran Pasien Rawat Jalan di UPT Rumah Sakit Khusus Mata medan dari 30 responden yang telah diteliti, mayoritas kurang puas sebanyak 13 responden (43.3\%), dan minoritas puas sebanyak 5 responden $(16.7 \%)$.

Tabel 4. Distribusi Frekuensi Kepuasan Pasien Pada Komunikasi Pendaftaran
Pasien Rawat Jalan di UPT Rumah Sakit Khusus Mata Medan

\begin{tabular}{clcc}
\hline No & Pelayanan & F & $(\mathbf{\% )}$ \\
\hline 1 & Tidak Puas & 8 & 26.7 \\
\hline 2 & Kurang Puas & 13 & 43.3 \\
\hline 3 & Puas & 9 & 30 \\
\hline & Total & $\mathbf{3 0}$ & $\mathbf{1 0 0}$ \\
\hline
\end{tabular}

Tabel diatas menunjukkan bahwa distribusi Kepuasan Pasien Pada Komunikasi Pendaftaran Pasien Rawat Jalan di UPT Rumah Sakit Khusus Mata medan dari 30 responden yang telah diteliti, mayoritas kurang puas sebanyak 13 responden $(43.3 \%)$, dan minoritas tidak puas sebanyak 8 responden $(26.7 \%)$.

Tabel 5. Distribusi Frekuensi Kepuasan Pasien Pada Waktu Tunggu Pendaftaran Pasien Rawat Jalan di UPT Rumah Sakit khusus Mata Medan

\begin{tabular}{cccc}
\hline No & Pelayanan & F & $(\boldsymbol{\%})$ \\
\hline 1 & Tidak Puas & 15 & 50 \\
\hline 2 & Kurang Puas & 12 & 40 \\
\hline 3 & Puas & 3 & 10 \\
\hline & Total & $\mathbf{3 0}$ & $\mathbf{1 0 0}$ \\
\hline
\end{tabular}

Tabel diatas menunjukkan bahwa distribusi Kepuasan Pasien Pada Waktu Tunggu Pendaftaran Pasien Rawat Jalan di UPT Rumah Sakit Khusus Mata medan dari 30 responden yang telah diteliti, mayoritas tidak puas sebanyak 15 responden $(50 \%)$, dan minoritas puas sebanyak 3 responden $(10 \%)$.

\section{PEMBAHASAN}

Kualitas pelayanan adalah keseluruhan ciri serta sifat dari suatu produk atau pelayanan yang berpegaruh pada kemampuannya untuk memuaskan kebutuhan yang tersirat. Dengan demikian yang dimaksud dengan mutu pelayanan kesehatan adalah yang menunjukkan pada tingkat kesempurnaan pelayanan kesehatan dalam menimbulkan rasa puas pada diri setiap pasien.

Berdasarkan tabel distribusi Kepuasan Pasien Pada Pelayanan Pendaftaran Pasien Rawat Jalan di UPT Rumah Sakit Khusus Mata medan dari 30 responden yang telah diteliti, mayoritas kurang puas sebanyak 13 responden $(43.3 \%)$, dan minoritas puas sebanyak 5 responden (16.7\%). 
Berdasarkan asumsi peneliti ditemukan pasien yang kurang puas terhadap pelayanan pendaftaran pasien rawat jalan di UPT rumah sakit mata sebanyak 13 responden $(43 \%)$. Hasil penelitian bertolak belakang dengan Kuntoro (2017) kepuasan pasien terhadap pelayanan di tempat pendaftaran pasien rawat jalan puskesmas kretek bentul yogyakarta yang menyatakan tidak ada responden yang kurang puas terhadap pelayanan di tempat pendaftaran rawat jalan.

Komunikasi adalah komunikasi yang direncanakan dan dilakukan bertujuan untuk membantu pelayanan pasien, petugas harrus memiliki keterampilan komunikasi yang bersifat profesional sehingga akan lebih efektif dalam mencapai tujuan memberikan kepuasan dalam pelayanan (Damayanti, 2008). Berdasarkan tabel 4.4 distribusi Kepuasan Pasien Pada Komunikasi Pendaftaran Pasien Rawat Jalan di UPT Rumah Sakit Khusus Mata medan dari 30 responden yang telah diteliti, mayoritas kurang puas sebanyak 13 responden $(43.3 \%)$, dan minoritas tidak puas sebanyak 8 responden $(26.7 \%)$.

Berdasarkan asumsi peneliti ditemukan pasien yang kurang puas terhadap komunikasi di tempat pendaftaran rawat jalan di UPT Rumah Sakit Khusus Mata Medan sebanyak 13 responden (43.3\%). Hasil penelitian sejalan dengan Mustaflah (2015) yang menyatakan pasien kurang puas terhadap komunikasi petugas $63.5 \%$.

waktu tunggu adalah waktu yang digunakan pasien untuk mendapatkan pelayanan kesehatan yang di gunakan pasien untuk mendapatkan pelayanan kesehatan mulai tempat pendaftaran sampai masuk keruang tunggu dokter. Berdasarkan tabel 4.3 distribusi Kepuasan Pasien Pada Waktu Tunggu Pendaftaran Pasien Rawat Jalan di UPT Rumah Sakit Khusus Mata medan dari 30 responden yang telah diteliti, mayoritas tidak puas sebanyak 15 responden (50\%), dan minoritas puas sebanyak 3 responden (10\%).

Berdasarkan asumsi peneliti ditemukan pasien yang tidak puas terhadap Waktu tunggu di tempat pendaftaran rawat jalan di
UPT Rumah Sakit Khusus Mata Medan sebanyak 15 responden (50\%).

\section{KESIMPULAN}

Berdasarkan hasil penelitian yang telah dilakukan dengan judul Tinjauan Kepuasan Pasien Terhadap Pelayanan Pendaftaran Rawat Jalan Di UPT Rumah Sakit Khusus Mata Medan, maka dapat disimpulkan :

1. Kepuasan Pasien Pada Pelayanan Pendaftaran Pasien Rawat Jalan di UPT

Rumah Sakit Khusus Mata Medan dari 30 responden yang telah diteliti, mayoritas kurang puas sebanyak 13 responden $(43 \%)$, dan minoritas puas sebanyak 5 responden (16.7\%).

2. Kepuasan Pasien Pada Komunikasi Pendaftaran Pasien Rawat Jalan di UPT Rumah Sakit Khusus Mata Medan dari 30 responden yang telah diteliti, mayoritas kurang puas sebanyak 13 responden (43.3\%), dan minoritas tidak puas sebanyak 8 responden (26.7\%).

3. Kepuasan Pasien Pada Waktu Tunggu Pendaftaran Pasien Rawat Jalan di UPT Rumah Sakit Khusus Mata Medan dari 30 responden yang telah diteliti, mayoritas tidak puas sebanyak 15 responden $(50 \%)$, dan minoritas puas sebanyak 3 responden (10\%).

\section{DAFTAR PUSTAKA}

Arikunto, Suharsini. (2010). Prosedur Penelitian Suatu Pendekatan Praktik. Jakarta: Rineka Cipta.

Rustiyanto, Ery. (2009). Etika Profesi Rekam Medis dan Informasi Kesehatan. Jakarta: Graha Ilmu.

Imbalo, S, Pohan. (2013). Jaminan Mutu Layanan Kesehatan. Jakarta: Buku Kedokteran EGC.

Manulang M, Novia. (2017). Analisa Tingkat Kepuasan Pasien Di Unit Pendaftaran Pasien Rawat Jalan di RSU Mitra Medika Medan Tahun 2017. Karya Tulis Ilmiah Apikes Imelda Medan.

Notoatmojo, Soekidjo. (2012). Metode Penelitian Kesehatan. Jakarta: Rineka Cipta. 
Peraturan Menteri Kesehatan Republik Indonesia. (2008). Nomor 269 Tahun 2008 "Tentang Isi Berkas Rekam Medis". Jakarta: Kemenkes RI.
Saryono, Dwi Anggraeni Mekar. (2013). Metode Penelitian Kesehatan. Jakarta: Kencana Prenada Media Group.

Savitri, C. Budi. (2011). Manajemen Unit Kerja Rekam Medis. Jogyakarta: Quantum Sinergis Media. 